RESEARCH BRIEF

\title{
Chronic Health Conditions Among US Veterans Discharged From Military Service for Misconduct
}

\author{
Emily Brignone, PhD ${ }^{1,3}$; J.D. Fargo ${ }^{2,3}$; R.K. Blais ${ }^{2,3}$; A.V. Gundlapalli ${ }^{2,4}$
}

Accessible Version: www.cdc.gov/pcd/issues/2018/18_0238.htm

Suggested citation for this article: Brignone E, Fargo J, Blais R, Gundlapalli A. Chronic Health Conditions Among US Veterans Discharged From Military Service for Misconduct. Prev Chronic Dis 2018;15:180238. DOI: https://doi.org/10.5888/pcd15.180238.

\section{PEER REVIEWED}

\section{Abstract}

Veterans who are discharged from military service due to misconduct are vulnerable to negative health-related outcomes, including homelessness, incarceration, and suicide. We used national data from the Veterans Health Administration for 218,608 veterans of conflicts in Iraq and Afghanistan that took place after the events of September 11, 2001, to compare clinical diagnoses between routinely-discharged $(n=203,174)$ and misconduct-discharged $(n$ $=15,433)$ veterans. Misconduct-discharged veterans had significantly higher risk for all mental health conditions (adjusted odds ratio [AOR] range, 2.5-8.0) and several behaviorally linked chronic health conditions (AOR range, 1.2-5.9). Misconduct-discharged veterans have serious and complex health care needs; prevention efforts should focus on behavioral risk factors to prevent the development and exacerbation of chronic health conditions among this vulnerable population.

\section{Objective}

Approximately $15 \%$ of recent US veterans were discharged from military service for misconduct (1). Compared with routinely-discharged veterans, misconduct-discharged veterans have high risk for incarceration, homelessness, and suicide (2-4). Studies have identified mental health disparities among this population (5), but how misconduct discharge relates to risk for chronic health conditions is unknown. Understanding the prevalence of chronic health conditions among this vulnerable population is important for understanding treatment needs and for identifying opportunities to integrate chronic disease prevention into clinical care. The purpose of this study was to compare comorbidities between misconduct-discharged and routinely-discharged US veterans.

\section{Methods}

Data for this study were extracted from national Veterans Health Administration (VHA) databases and included records from 2006 through 2015 for 218,608 active-duty veterans of conflicts in Iraq and Afghanistan that took place after the events of September 11, 2001 (9/11). Demographic variables were age, sex, race/ethnicity, educational status, marital status, branch of service, rank, and type of discharge. Clinical data included diagnoses assigned by VHA providers during clinical encounters. Five years of retrospective follow-up data were included for each veteran, beginning on the date of each veteran's initial VHA encounter. Analyses were conducted with R (6) and Stata (7) software through the VA's secure VINCI workspace (8). The study was approved by the VA Salt Lake City Health Care System and the University of Utah institutional review boards.

Discharge type. Interservice Separation Codes, which indicate the circumstances related to separation from military service, were classified (5). Those with a "routine" or "misconduct-related" classification were included in this study.

Health status. The enhanced Elixhauser comorbidity index algorithm was used to create a set of 31 binary physical and mental health diagnostic outcomes, indicating the presence or absence of major chronic health conditions (9). Veterans with one primary diagnosis or more within a given category were considered to be positive. Certain outcomes categories (eg, human immunodeficiency virus (HIV), peptic ulcer disease, weight loss), were selfexplanatory. For the rest, the HCUP Clinical Classification System (10) was used to create meaningful subcategories that describe the types of conditions that comprise each outcome. Subcategories were not exhaustive but provided high coverage of common conditions.

Data analysis. We computed descriptive statistics for all study variables. Health status variables served as binary outcomes in a 
series of Firth logistic regression models, which were used because of the low prevalence of certain conditions (11). The primary predictor variable was discharge type (routine vs misconduct). Covariates were age, sex, education status, marital status, race/ethnicity, branch of service, and rank. We computed separate models for men and women. Because of the large number of statistical tests conducted, an $\alpha$ level of .01 was used. We calculated adjusted odds ratios (AORs) and 99\% confidence intervals. We computed subcategory frequencies for outcomes in which significant differences were found.

\section{Results}

Compared with routinely-discharged veterans, misconduct-discharged veterans had lower levels of education and more were unmarried, served in the Army, and were of enlisted rank (Table 1). At the beginning of follow up, the average age of the sample was 26.7 years for misconduct-discharged veterans and 31.6 years for routinely-discharged veterans.

Misconduct discharge was significantly associated with higher risk for several conditions (Table 2). Among men, misconduct discharge was associated with significantly higher odds for cardiac arrhythmias $(\mathrm{AOR}=1.2)$, paralysis $(\mathrm{AOR}=2.1)$, neurological disorders $(\mathrm{AOR}=2.1)$, chronic pulmonary disease $(\mathrm{AOR}=1.3)$, liver disease $(\mathrm{AOR}=1.6)$, peptic ulcer disease $(\mathrm{AOR}=1.5)$, acquired immunodeficiency syndrome $(\mathrm{AIDS}) / \mathrm{HIV}(\mathrm{AOR}=3.3)$, weight loss $(\mathrm{AOR}=1.4)$, and fluid and electrolyte disorders (AOR $=1.7$ ).

Among women, misconduct discharge was associated with significantly higher odds for neurological disorders $(\mathrm{AOR}=2.8)$, chronic pulmonary disease $(\mathrm{AOR}=1.4)$, liver disease $(\mathrm{AOR}=$ $2.5)$, peptic ulcer disease $(\mathrm{AOR}=4.2)$, metastatic cancer $(\mathrm{AOR}=$ 5.9 ), solid tumor without metastasis ( $\mathrm{AOR}=2.0$ ), and weight loss $(\mathrm{AOR}=2.1)$.

Men and women with a misconduct discharge had higher odds for alcohol abuse, drug abuse, depression, and psychosis (AOR range, 2.5-8.0). For mental health-related outcomes, the presence of diagnoses in multiple subcategories was more common among misconduct-discharged veterans, indicating higher comorbidity (Table 3).

\section{Discussion}

Misconduct-discharged veterans experience significant disparities in several chronic health conditions, many of which are behaviorally linked, including chronic pulmonary disease, liver disease, and AIDS/HIV. These disparate risks likely relate to the unique mental and behavioral health characteristics of this population.
Specifically, misconduct may occur as a result of poor executive functioning and decision making while in service, sometimes caused by unmet or unrecognized mental health needs. Following discharge, these factors may continue to drive health and social outcomes.

Targeted prevention efforts in the VHA may help mitigate the vulnerabilities of this population. Integrating chronic disease prevention into the mental health and social services that misconduct-discharged veterans are likely to use may be an effective strategy. In addition, transitioning the care of misconduct-discharged veterans from acute settings into integrated primary care settings such as patient-centered medical homes may enable the VHA to more efficiently meet their complex health needs.

This study has limitations. Diagnostic codes may contain errors, and codes may be applied inconsistently across providers. Certain findings, such as high incidence of rare conditions such as cardiac arrhythmias, merit further study. This sample is based on users of VHA care, and there may be differences between those who do and do not access VHA services. We are also unable to assess non-VHA health service use, and we did not include information relating to service-connected disability benefit level, which may factor into the decision to use VHA services. Future research should assess symptoms among a broader sample of veterans that include older cohorts, because disparities may multiply with increasing age.

Results from this study demonstrate that misconduct discharge can be a marker for behaviorally linked chronic health conditions, and they underscore the reciprocal relationship between mental and physical health in both military and civilian settings. Strategies for improving outcomes among this vulnerable population may include targeted screening for risky health behaviors and early signs of chronic health conditions and the integration of preventive care with mental and behavioral care.

\section{Acknowledgments}

The authors received administrative support from the Informatics, Decision Enhancement, and Analytic Sciences Center (IDEAS 2.0) at VA Salt Lake City, the University of Utah, and Utah State University. This study was not directly funded through a grant, although study authors receive research support from VA Health Services Research and Development (PI: A.V. Gundlapalli). The US Department of Veterans Affairs had no role in the design, conduct, or interpretation of this study or the decision to submit the manuscript for publication. The views expressed in this article are those of the authors and do not necessarily represent the views, The opinions expressed by authors contributing to this journal do not necessarily reflect the opinions of the U.S. Department of Health and Human Services,
the Public Health Service, the Centers for Disease Control and Prevention, or the authors' affiliated institutions. 
position, or policy of the US Department of Veterans Affairs or the US government. No copyrighted materials, surveys, instruments, or tools were used in this paper.

\section{Author Information}

Corresponding Author: Emily Brignone, PhD, VA Pittsburgh Healthcare System, University Drive 151C, Pittsburgh, PA 152401001. Telephone: 412-360-2236. Email: emily.brignone@va.gov.

Author Affiliations: ${ }^{1}$ Center for Health Equity Research and Promotion, VA Pittsburgh Healthcare System, Pittsburgh, Pennsylvania. ${ }^{2}$ Informatics, Decision Enhancement, and Analytic Sciences Center, VA Salt Lake City Health Care System, Salt Lake City, Utah. ${ }^{3}$ Department of Psychology, Utah State University, Logan, Utah. ${ }^{4}$ Departments of Internal Medicine and Biomedical Informatics, University of Utah School of Medicine, Salt Lake City, Utah.

\section{References}

1.US Department of Defense Manpower Data Center. Interservice Separation Codes for Active Separations. http:// www.esd.whs.mil/Portals/54/Documents/FOID/ Reading\%20Room/Statistical_Data/13-F-0059_Separations Code_FY01-12.xlsx. Accessed February 9, 2018.

2. Noonan ME, Mumola CJ. Veterans in state and federal prison. From the Bureau of Justice Statistics Special Report. Washington (DC): US Department of Justice; 2004.

3. Gundlapalli AV, Fargo JD, Metraux S, Carter ME, Samore $\mathrm{MH}$, Kane V, et al. Military misconduct and homelessness among us veterans separated from active duty, 2001-2012. JAMA 2015;314(8):832-4.

4. Reger MA, Smolenski DJ, Skopp NA, Metzger-Abamukang MJ, Kang HK, Bullman TA, et al. Risk of suicide among US military service members following Operation Enduring Freedom or Operation Iraqi Freedom deployment and separation from the US military. JAMA Psychiatry 2015; 72(6):561-9.

5. Brignone E, Fargo JD, Blais RK, Carter ME, Samore MH, Gundlapalli AV. Non-routine discharge from military service: mental illness, substance use disorders, and suicidality. Am J Prev Med 2017;52(5):557-65.

6. R Core Team. R: a language and environment for statistical computing. Vienna, Austria: R Foundation for Statistical Computing. https://www.R-project.org/. Accessed February 6, 2018.

7. Stata Statistical Software: release 14; 2014. College Station (TX): StataCorp LP.
8. US Department of Veterans Affairs. VA Informatics and Computing Infrastructure (VINCI); 2018. http:// www.hsrd.research.va.gov/for_researchers/vinci/. Accessed February 6, 2018.

9. Quan H, Sundararajan V, Halfon P, Fong A, Burnand B, Luthi $\mathrm{JC}$, et al. Coding algorithms for defining comorbidities in ICD9-CM and ICD-10 administrative data. Med Care 2005; 43(11):1130-9.

10. HCUP Clinical Classifications Software (CCS) for ICD-9-CM. Healthcare Cost and Utilization Project (HCUP), 2006-2009. Rockville (MD): Agency for Healthcare Research and Quality.

11. Heinze G, Schemper M. A solution to the problem of separation in logistic regression. Stat Med 2002; 21(16):2409-19.

The opinions expressed by authors contributing to this journal do not necessarily reflect the opinions of the U.S. Department of Health and Human Services, the Public Health Service, the Centers for Disease Control and Prevention, or the authors' affiliated institutions. 


\section{Tables}

Table 1. Demographic and Military Service Characteristics of Active Duty Veterans of Post-9/11 Conflicts in Iraq and Afghanistan ( $\mathrm{N}=218,608)$, Veterans Health Administration, 2006-2015

\begin{tabular}{|c|c|c|c|c|}
\hline \multirow[b]{2}{*}{ Characteristic } & \multicolumn{2}{|c|}{ Women $^{a}$} & \multicolumn{2}{|c|}{$\operatorname{Men}^{a}$} \\
\hline & Routine $(\mathrm{N}=20,835)$ & Misconduct $(\mathrm{N}=1,263)$ & Routine ( $\mathrm{N}=182,339)$ & Misconduct $(\mathrm{N}=14,170)$ \\
\hline Mean age at first encounter, $y$ (SD) & $31.5(8.4)$ & $26.7(5.2)$ & $31.6(8.7)$ & $26.7(4.6)$ \\
\hline \multicolumn{5}{|l|}{ Race/ethnicity } \\
\hline White & $9,804(47.1)$ & 569 (45.1) & $112,874(61.9)$ & $8,431(59.5)$ \\
\hline Black & $5,938(28.5)$ & $488(38.6)$ & $26,287(14.4)$ & $3,463(24.4)$ \\
\hline Hispanic & $2,431(11.7)$ & $118(9.3)$ & $20,498(11.2)$ & $1,490(10.5)$ \\
\hline Other/unknown & $2,662(12.8)$ & $88(7.0)$ & $22,680(12.4)$ & $786(5.5)$ \\
\hline \multicolumn{5}{|l|}{ Education level } \\
\hline High school/equivalent & $15,912(77.7)$ & $1,127(90.7)$ & $151,753(84.6)$ & 13,077 (93.9) \\
\hline Beyond high school & 4,577 (22.3) & $116(9.3)$ & $27,672(15.4)$ & $846(6.1)$ \\
\hline \multicolumn{5}{|l|}{ Marital status } \\
\hline Never married & $11,709(56.4)$ & $856(68)$ & $100,536(55.2)$ & $9,685(68.4)$ \\
\hline Married & $7,631(36.7)$ & $356(28.3)$ & $77,184(42.4)$ & $4,292(30.3)$ \\
\hline Divorced/other & $1,430(6.9)$ & $46(3.7)$ & $4,402(2.4)$ & $177(1.3)$ \\
\hline \multicolumn{5}{|l|}{ Branch of service } \\
\hline Army & $8,041(38.6)$ & $720(57.0)$ & $74,437(40.8)$ & $8,674(61.2)$ \\
\hline Marines & $1,832(8.8)$ & $44(3.5)$ & $46,560(25.5)$ & $1,375(9.7)$ \\
\hline Air Force & 5,389 (25.9) & $234(18.5)$ & $26,384(14.5)$ & $1,345(9.5)$ \\
\hline Navy/Coast Guard & $5,573(26.7)$ & 265 (21.0) & 34,956 (19.2) & $2,776(19.6)$ \\
\hline \multicolumn{5}{|l|}{ Rank } \\
\hline Enlisted & $18,994(91.2)$ & $1,212(96.0)$ & $169,982(93.2)$ & 13,874 (97.9) \\
\hline Officer/Warrant & $1,841(8.8)$ & $51(4.0)$ & $12,357(6.8)$ & $296(2.1)$ \\
\hline
\end{tabular}

Abbreviations: 9/11, the events of September 11, 2001; SD, standard deviation.

${ }^{a}$ Values are no. (\%) unless otherwise indicated. 
Table 2. Frequencies and Adjusted Risk for Clinical Comorbidities Over 5 Years of Follow-Up Among Active Duty Veterans of Post-9/11 Conflicts in Iraq and Afghanistan $(\mathrm{N}=\mathbf{2 1 8}, 608)$, Veterans Health Administration, 2006-2015

\begin{tabular}{|c|c|c|c|c|c|c|}
\hline \multirow[b]{3}{*}{ Elixhauser Category } & \multicolumn{3}{|c|}{ Women } & \multicolumn{3}{|c|}{ Men } \\
\hline & $\begin{array}{c}\text { Routine } \\
(N=20,835)\end{array}$ & $\begin{array}{l}\text { Misconduct } \\
(\mathrm{N}=1,263)\end{array}$ & \multirow[b]{2}{*}{$\mathrm{AOR}^{\mathrm{a}}(99 \% \mathrm{Cl})$} & $\begin{array}{c}\text { Routine } \\
(\mathrm{N}=182,339)\end{array}$ & $\begin{array}{c}\text { Misconduct } \\
(\mathrm{N}=14,170)\end{array}$ & \multirow[b]{2}{*}{$\mathrm{AOR}^{\mathrm{a}}(99 \% \mathrm{Cl})$} \\
\hline & \multicolumn{2}{|c|}{ No. (\%) } & & \multicolumn{2}{|c|}{ No. (\%) } & \\
\hline Congestive heart failure & $34(0.2)$ & $3(0.2)$ & $2.13(0.48-9.54)$ & $324(0.2)$ & $28(0.2)$ & $1.44(0.84-2.47)$ \\
\hline Cardiac arrhythmias & $464(2.2)$ & $30(2.4)$ & $1.03(0.61-1.72)$ & $4,002(2.2)$ & $381(2.7)$ & $1.21(1.05-1.41)$ \\
\hline Valvular disease & $76(0.4)$ & $4(0.3)$ & $1.20(0.33-4.30)$ & $460(0.3)$ & $29(0.2)$ & $0.97(0.58-1.62)$ \\
\hline Pulmonary circulation disorders & $37(0.2)$ & $4(0.3)$ & $2.41(0.62-9.36)$ & $220(0.1)$ & $23(0.2)$ & $1.32(0.72-2.43)$ \\
\hline Peripheral vascular disorders & $40(0.2)$ & $2(0.2)$ & $1.64(0.29-9.14)$ & $354(0.2)$ & $28(0.2)$ & $1.58(0.93-2.70)$ \\
\hline Hypertension, uncomplicated & $1,658(8.0)$ & $86(6.8)$ & $1.32(0.97-1.81)$ & $21,623(11.9)$ & $1,299(9.2)$ & $1.02(0.94-1.10)$ \\
\hline Hypertension, complicated & $15(0.1)$ & $1(0.1)$ & $1.97(0.18-21.00)$ & $200(0.1)$ & $15(0.1)$ & $1.30(0.64-2.67)$ \\
\hline Paralysis & $24(0.1)$ & $1(0.1)$ & $0.95(0.10-8.90)$ & $269(0.1)$ & $42(0.3)$ & $2.05(1.30-3.24)$ \\
\hline Other neurological disorders & $212(1.0)$ & $43(3.4)$ & $2.84(1.77-4.57)$ & $1,972(1.1)$ & $376(2.7)$ & $2.14(1.82-2.50)$ \\
\hline Chronic pulmonary disease & $1,642(7.9)$ & $143(11.3)$ & $1.35(1.05-1.73)$ & $8,993(4.9)$ & $992(7)$ & $1.31(1.20-1.44)$ \\
\hline Diabetes, uncomplicated & 389 (1.9) & $17(1.3)$ & $1.03(0.53-2.23)$ & $4,285(2.4)$ & $196(1.4)$ & $1.05(0.86-1.28)$ \\
\hline Diabetes, complicated & $30(0.1)$ & $0(0.0)$ & $0.41(0.01-17.00)$ & $457(0.3)$ & $28(0.2)$ & $1.45(0.86-2.44)$ \\
\hline Hypothyroidism & $826(4.0)$ & $42(3.3)$ & $1.07(0.70-1.64)$ & $1,783(1.0)$ & $104(0.7)$ & $0.88(0.67-1.16)$ \\
\hline Renal failure & $27(0.1)$ & $1(0.1)$ & $1.63(0.17-15.76)$ & $556(0.3)$ & $43(0.3)$ & $1.16(0.74-1.80)$ \\
\hline Liver disease & $103(0.5)$ & $12(10.0)$ & $2.52(1.10-5.81)$ & $1,519(0.8)$ & $168(1.2)$ & $1.58(1.27-1.98)$ \\
\hline Peptic ulcer disease & $42(0.2)$ & $8(0.6)$ & $4.22(1.51-11.83)$ & $411(0.2)$ & $56(0.4)$ & $1.54(1.04-2.29)$ \\
\hline AIDS/HIV & $11(0.1)$ & $2(0.2)$ & $3.45(0.48-25.02)$ & $237(0.1)$ & $88(0.6)$ & $3.30(2.33-4.65)$ \\
\hline Lymphoma & $19(0.1)$ & $0(0.0)$ & $0.79(0.19-33.61)$ & $171(0.1)$ & $13(0.1)$ & $1.17(0.55-2.50)$ \\
\hline Metastatic cancer & $15(0.1)$ & $3(0.2)$ & $5.87(1.03-33.84)$ & $114(0.1)$ & $13(0.1)$ & $1.56(0.70-3.47)$ \\
\hline Solid tumor without metastasis & $231(1.1)$ & $18(1.4)$ & $1.96(1.01-3.84)$ & $1,119(0.6)$ & $70(0.5)$ & $1.10(0.79-1.54)$ \\
\hline RA/collagen vascular diseases & $292(1.4)$ & $14(1.1)$ & $0.98(0.48-2.00)$ & $1,030(0.6)$ & $90(0.6)$ & $1.16(0.86-1.56)$ \\
\hline Coagulopathy & $44(0.2)$ & $5(0.4)$ & $2.20(0.85-7.47)$ & $338(0.2)$ & $26(0.2)$ & $0.98(0.57-1.67)$ \\
\hline Obesity & $1,854(8.9)$ & $125(9.9)$ & $1.11(0.86-1.44)$ & $10,164(5.6)$ & $686(4.8)$ & $0.81(0.73-0.91)$ \\
\hline Weight loss & $102(0.5)$ & $15(1.2)$ & $2.13(1.02-4.43)$ & $567(0.3)$ & $82(0.6)$ & $1.41(1.02-1.95)$ \\
\hline Fluid and electrolyte disorders & $170(0.8)$ & $15(1.2)$ & $1.57(0.77-3.20)$ & $862(0.5)$ & $130(0.9)$ & $1.74(1.34-2.25)$ \\
\hline Blood loss anemia & $31(0.1)$ & $2(0.2)$ & $1.35(0.23-7.89)$ & $26(0.0)$ & $2(0.0)$ & $1.15(0.19-6.90)$ \\
\hline Deficiency anemia & $383(1.8)$ & $27(2.1)$ & $1.21(0.71-2.05)$ & $403(0.2)$ & $26(0.2)$ & $0.86(0.50-1.48)$ \\
\hline Alcohol abuse & $604(2.9)$ & $221(17.5)$ & $5.58(4.42-7.07)$ & $13,557(7.4)$ & $3,558(25.1)$ & $3.44(3.25-3.65)$ \\
\hline Drug abuse & $363(1.7)$ & $215(17)$ & $8.04(6.22-10.40)$ & $7,666(4.2)$ & 3,339 (23.6) & $5.14(4.82-5.49)$ \\
\hline Psychoses & $308(1.5)$ & $63(5.0)$ & $2.84(2.40-3.34)$ & $2850(1.6)$ & $838(5.9)$ & $2.46(2.34-2.60)$ \\
\hline Depression & $8,011(38.4)$ & $855(67.7)$ & $2.97(2.02-4.38)$ & 73,047 (40.1) & $9,566(67.5)$ & $2.95(2.64-3.30)$ \\
\hline
\end{tabular}

Abbreviations: 9/11, the events of September 11, 2001; AIDS, acquired immunodeficiency syndrome; AOR, adjusted odds ratio; Cl, confidence interval; HIV, human immunodeficiency virus; RA, rheumatoid arthritis.

${ }^{a}$ Odds adjusted for age, race/ethnicity, marital status, education, branch of service, and rank.

The opinions expressed by authors contributing to this journal do not necessarily reflect the opinions of the U.S. Department of Health and Human Services, the Public Health Service, the Centers for Disease Control and Prevention, or the authors' affiliated institutions. 
Table 3. Frequencies and Descriptions for Subcategories Composing Selected Categories of Comorbidity Over 5 Years of VHA Follow-Up Among Active Duty Veterans of Post-9/11 Conflicts in Iraq and Afghanistan ( $N=218,608)$, Veterans Health Administration, 2006-2015

\begin{tabular}{|c|c|c|c|c|}
\hline \multirow[b]{2}{*}{ Elixhauser Category } & \multicolumn{2}{|c|}{ Women, $\%^{\mathrm{a}}$} & \multicolumn{2}{|c|}{ Men, $\%^{a}$} \\
\hline & Routine & Misconduct & Routine & Misconduct \\
\hline \multicolumn{5}{|l|}{ Cardiac arrhythmias } \\
\hline Cardiac dysrhythmias & & - & 96.5 & 94.8 \\
\hline Conduction disorders & & - & 5.8 & 8.4 \\
\hline \multicolumn{5}{|l|}{ Paralysis } \\
\hline Other paralysis & & - & 85.5 & 88.1 \\
\hline Hemiplegia & & - & 14.1 & 7.1 \\
\hline Other central nervous system disorder & & - & 5.9 & 11.9 \\
\hline \multicolumn{5}{|l|}{ Other neurological disorders } \\
\hline Convulsions & 63.2 & 79.1 & 71.1 & 80.6 \\
\hline Epilepsy & 31.1 & 51.2 & 31.9 & 31.4 \\
\hline Hereditary and degenerative nervous system conditions & 25.5 & 4.7 & 13.1 & 5.1 \\
\hline \multicolumn{5}{|l|}{ Chronic pulmonary disease } \\
\hline Other and unspecific asthma & 67.7 & 53.1 & 58.7 & 54.3 \\
\hline Other chronic pulmonary disease & 30.9 & 49.0 & 32.8 & 43.5 \\
\hline Chronic airway obstruction; not otherwise specified & 8.5 & 6.3 & 13.2 & 9.5 \\
\hline \multicolumn{5}{|l|}{ Liver disease } \\
\hline Hepatitis & 37.9 & 66.7 & 35.9 & 61.9 \\
\hline Other liver diseases & 58.3 & 25.0 & 58.7 & 31.5 \\
\hline Alcohol - related disorders & 5.8 & 8.3 & 12.7 & 16.1 \\
\hline \multicolumn{5}{|l|}{ Metastatic cancer } \\
\hline Malignancy without site specification & 53.3 & 33.3 & & - \\
\hline Secondary malignancy of lymph nodes & 26.7 & 66.7 & & - \\
\hline Secondary malignancy of bone & 13.3 & 0 & & - \\
\hline Secondary malignancy of brain/spine & 6.7 & 33.3 & & - \\
\hline Secondary malignancy of liver & 6.7 & 0 & & - \\
\hline \multicolumn{5}{|l|}{ Solid tumor without metastasis } \\
\hline Cancer of breast & 32.5 & 22.2 & & - \\
\hline Cancer; other primary & 29.0 & 38.9 & & - \\
\hline Cancer of uterus and cervix & 13.9 & 16.7 & & - \\
\hline Cancer of skin & 11.3 & 5.6 & & - \\
\hline Cancer of ovary and other female genital organs & 9.1 & 5.6 & & - \\
\hline Cancer of bronchus; lung & 2.2 & 5.6 & & - \\
\hline
\end{tabular}

Abbreviation: 9/11, the events of September 11, 2001.

${ }^{a}$ Percentage of veterans within each Elixhauser comorbidity category who have a diagnosis in the given subcategory. Subcategory tabulations are presented for selected categories where significant differences between discharge types were observed. The most common subcategories were selected for presentation. Totals may exceed $100 \%$ due to co-occurring conditions within the same Elixhauser category. 
(continued)

Table 3. Frequencies and Descriptions for Subcategories Composing Selected Categories of Comorbidity Over 5 Years of VHA Follow-Up Among Active Duty Veterans of Post-9/11 Conflicts in Iraq and Afghanistan ( $N=218,608)$, Veterans Health Administration, 2006-2015

\begin{tabular}{|c|c|c|c|c|}
\hline \multirow[b]{2}{*}{ Elixhauser Category } & \multicolumn{2}{|c|}{ Women, $\%^{a}$} & \multicolumn{2}{|c|}{ Men, $\%^{a}$} \\
\hline & Routine & Misconduct & Routine & Misconduct \\
\hline \multicolumn{5}{|l|}{ Fluid and electrolyte disorders } \\
\hline Hypovolemia & & - & 47.0 & 59.2 \\
\hline Hypopotassemia & & - & 30.7 & 26.9 \\
\hline Hyperpotassemia & & - & 13.7 & 6.9 \\
\hline \multicolumn{5}{|l|}{ Drug abuse } \\
\hline Drug use disorder, unspecified & 71.1 & 68.8 & 70.3 & 71.2 \\
\hline Opioid use disorder & 15.7 & 21.9 & 24.0 & 25.4 \\
\hline Cannabis use disorder & 30.0 & 40.9 & 28.0 & 37.5 \\
\hline Cocaine use disorder & 11.8 & 26.5 & 11.5 & 19.4 \\
\hline Amphetamine use disorder & 7.4 & 8.8 & 6.0 & 9.3 \\
\hline \multicolumn{5}{|l|}{ Psychosis } \\
\hline Schizophrenia and other psychotic disorders & 48.4 & 66.7 & 58.0 & 74.6 \\
\hline Depressive disorders (with psychotic features) & 47.7 & 28.6 & 36.6 & 21.6 \\
\hline Bipolar disorders (with psychotic features) & 6.8 & 12.7 & 6.1 & 9.7 \\
\hline \multicolumn{5}{|l|}{ Depression } \\
\hline Post-traumatic stress disorder & 52.1 & 63.7 & 73.3 & 76.0 \\
\hline Depressive disorders (without psychotic features) & 69.4 & 72.0 & 45.6 & 55.6 \\
\hline Adjustment disorders & 30.1 & 31.2 & 29.3 & 29.3 \\
\hline
\end{tabular}

Abbreviation: 9/11, the events of September 11, 2001.

${ }^{a}$ Percentage of veterans within each Elixhauser comorbidity category who have a diagnosis in the given subcategory. Subcategory tabulations are presented for selected categories where significant differences between discharge types were observed. The most common subcategories were selected for presentation. Totals may exceed $100 \%$ due to co-occurring conditions within the same Elixhauser category. 